\section{Revista Thema}

V.18 Especial 2020

p. $70-91$

\title{
Movimento paraolímpico brasileiro nos ensejos da pandemia de COVID-19: isolamento social e representações sociais na mídia digital
}

\section{Brazilian paralympic movement in the pandemic ensures of COVID-19: social isolation and social representations in digital} media

Giandra Anceski Bataglion', Janice Zarpellon Mazo²

\section{RESUMO}

Este estudo buscou averiguar as representações sociais acerca do esporte paraolímpico nacional diante da pandemia de COVID-19 nas notícias veiculadas pelo site do Comitê Paralímpico Brasileiro (CPB). Foram catalogadas as notícias do período de 16 de março ao dia primeiro de junho de 2020. A análise das informações evidenciou que a pandemia suscitou, inicialmente, a suspensão das atividades do Centro de Treinamento Paraolímpico Brasileiro. A partir disto, uma série de estratégias digitais foi adotada pelo CPB sendo, primeiramente, as "Lives com Profissionais da Natação Paralímpica" e o "Programa de Acompanhamento aos Atletas em Quarentena". Após o período aproximado de um mês, novas ações foram apresentadas, com destaque para duas: "Live Paralímpica" e "Live \#Tamo Junto". Ademais, foi lançado o "Programa Movimente-se". Também foram noticiados casos de falecimento e de doping de atletas paraolímpicos, nota de repúdio a humoristas, dentre outras atualizações do cenário paraolímpico mundial. Notou-se que o CPB procurou, pelos meios digitais, manter ativo o movimento paraolímpico brasileiro, exercendo proeminente papel às representações sociais que circundam a pessoa com deficiência.

Palavras-chave: Pessoa com deficiência; atletas paraolímpicos; esporte paraolímpico; Coronavírus; quarentena.

\section{ABSTRACT}

This study sought to ascertain the social representations about national Paralympic sport in the face of the COVID-19 pandemic in the news published on the website of the Brazilian Paralympic Committee (CPB). The news from the period from March 16 to June 1, 2020 were cataloged. The analysis of the information showed that the pandemic initially caused the suspension of the activities of the Brazilian Paralympic Training Center. From this, a series of digital strategies was adopted by the CPB, being, first, the "Lives with Paralympic Swimming

\footnotetext{
${ }^{1}$ Universidade Federal do Rio Grande do Sul - UFRGS, Porto Alegre/RS - Brasil. E-mail: giandraanceski@gmail.com

${ }^{2}$ Idem. E-mail: janice.mazo@ufrgs.br
} 
Professionals" and the "Quarantine Athletes Accompaniment Program". After a period of approximately one month, new shares were presented, with emphasis on two: "Live Paralympic" and "Live \#We're Together". In addition, the "Move Program" was launched. There were also reported cases of death and doping of Paralympic athletes, a note of disgust to comedians, among other updates on the world Paralympic scene. It was noted that the CPB sought, by digital means, to keep the Brazilian Paralympic movement active, playing a prominent role in the social representations surrounding the person with disabilities.

Keywords: Disabled person; paralympic athletes; paralympic sport; Coronavirus; quarantine.

\section{INTRODUÇÃO}

A pandemia de COVID-19 causou amplas transformações nos modos de vida da sociedade mundial, impactando não somente na saúde das pessoas, mas em grande medida nas atividades de trabalho, de lazer, na educação e no esporte. (DIAS, 2020). De acordo com a Organização das Nações Unidas (ONU) em documento datado de maio de 2020 (ONU, 2020), se trata de uma crise humana sem precedentes que causa impactos desproporcionalmente maiores a milhões de pessoas com deficiência no mundo. Nesse sentido, no contexto esportivo, assim como o esporte olímpico, o paraolímpico foi afetado pelas modificações que emergiram junto ao novo coronavírus, tendo em suas entidades a expectativa de encontrar estratégias, alternativas e incentivos à continuidade dos treinamentos de atletas, reduzindo os impactos ao futuro retorno às competições e ao movimento paraolímpico global.

O Comitê Paralímpico Brasileiro (CPB), fundado em 1995, é a entidade nacional filiada ao International Paralympic Committee (IPC) (Comitê Paralímpico Internacional), sendo responsável pelo esporte paraolímpico no Brasil. Além das ações relativas ao alto rendimento esportivo de atletas com deficiência, faz mais de uma década que o CPB atua no fomento à formação de base, desenvolvendo iniciativas como cursos de capacitação para professores de educação física e treinadores, projetos de iniciação esportiva, festivais paraolímpicos, competições escolares, dentre outras. (BATAGLION; MAZO, 2019). De tal modo, frequentemente, em seu site são noticiadas informações relativas a estas ações, além de aspectos do treinamento de atletas paraolímpicos(as), de competições nacionais e internacionais de modalidades paraolímpicas, assim como os resultados de seleções e atletas paraolímpicos(as) brasileiros(as), dentre outros acontecimentos atuais do movimento paraolímpico.

Com o anúncio da pandemia de COVID-19 no Brasil e a promulgação dos decretos de isolamento social, todos os eventos do esporte paraolímpico foram suspensos no país. Nessa direção, vale mencionar que o CPB esteve no protagonismo em decisões que visavam evitar a contaminação de pessoas, sobretudo envolvidas com o movimento paraolímpico, se posicionando desde o início favorável ao isolamento social e determinando a suspensão de atividades no Centro de Treinamento Paraolímpico Brasileiro (CT Paraolímpico), em São Paulo/SP. (CPB, 2020). Ainda no início do mês de 


\section{Edição Especial COVID-19}

fevereiro, quando o CT Paraolímpico ainda estava em funcionamento, com alta circulação de pessoas, incluindo atletas, treinadores, alunos(as) do Centro de Formação Esportiva e seus familiares, dentre tantas outras pessoas que trabalham na administração e manutenção do espaço, a entidade decidiu transferir e/ou cancelar campeonatos mundiais que estavam agendados para serem sediados no CT Paraolímpico. O primeiro caso foi relativo ao Brazil Para badminton International 2020, que ocorreu entre os dias 10 e 15 de fevereiro, no Ginásio do Ibirapuera, em São Paulo/SP. O segundo caso, se refere à "Copa do Mundo de São Paulo de Esgrima em Cadeira de Rodas", competição classificatória para os Jogos Paralímpicos (JP) de Tóquio 2020, que foi cancelada em caráter de urgência no dia dois de março de 2020, por decisão da International Wheelchair and Amputee Sports Federation (IWAS) (Federação Internacional de Esportes para Cadeirantes e Amputados). (CBE, 2020).

Conforme o presidente do CPB, Mizael Conrado de Oliveira, na época, a entidade responsável pelo esporte paraolímpico do Brasil sofreu muitas críticas pelo posicionamento quanto a não realização de eventos internacionais no CT Paraolímpico. As decisões foram consideradas por muitas pessoas e entidades nacionais e internacionais como precipitada e até mesmo preconceituosa. Em podcast sobre o esporte paraolímpico em tempos de pandemia, o presidente do CPB recordou que se ouvia dizer que o "Comitê Paralímpico Brasileiro estava matando o sonho dos irmãos chineses" (CPB, 2020), se referindo ao adiamento da competição classificatória aos JP de Tóquio 2020.

Em pouco tempo, a despeito das críticas, têm-se que o CPB tomou a decisão apropriada, visando preservar inúmeros envolvidos com o movimento paraolímpico, sobretudo, ao se considerar as pessoas com deficiência como integrantes do grupo de risco para COVID-19. (ONU, 2020). No mês de março de 2020, foram oficialmente suspensas todas as atividades do CT Paraolímpico, incluindo treinamentos com atletas e projetos escolares. Notou-se que aos poucos outras entidades esportivas do país passaram a aderir ao isolamento social, transformando os treinamentos de seus atletas em atividades remotas e suspendendo eventos agendados para os meses seguintes.

Notícias veiculadas nas mídias carregam mensagens e imagens, gerando interpretações conjuntamente em grupos sociais de modo a influenciar sua realidade cotidiana. (JODELET, 2001). No caso do CPB, o trabalho de mídia é proeminente na divulgação dos eventos, competições e de outras iniciativas do esporte paraolímpico, exercendo relevante papel no fortalecimento e na consolidação deste movimento no Brasil, gerando resultados positivos da iniciação ao alto rendimento. (CARDOSO et al., 2018). Nesse sentido, considerando o cenário de isolamento social e a interrupção das atividades do esporte paraolímpico nacional e internacional, chegou-se ao seguinte objetivo para este estudo: averiguar as representações sociais acerca do esporte paraolímpico nacional diante da pandemia de COVID-19 nas notícias veiculadas pelo site do Comitê Paralímpico Brasileiro. 


\section{PROCEDIMENTOS METODOLÓGICOS}

Este estudo foi realizado a partir da coleta de informações no site do CPB, do qual foram catalogadas as notícias, publicadas na aba "imprensa" do site, no período de 16 de março de 2020 a primeiro de junho de 2020. A data que demarca o recorte inicial do estudo foi definida em função na publicação da notícia intitulada "Comunicado oficial: suspensão e cancelamento das atividades". O nosso recorte final, por sua vez, condiz com fechamento do ciclo do primeiro mês de realização da ação intitulada "Live Paralímpica", bem como demarca o lançamento de nova iniciativa digital pela entidade. Ademais, nossa coleta de dados sucedeu entre os dias primeiro e três de junho de 2020, com sequência às etapas da análise temática de conteúdo. (FLICK, 2009). Deste modo, não foi possível considerar as notícias do mês de junho de 2020 para a elaboração deste estudo, embora tenhamos conhecimento de que os desdobramentos de ações e notícias envolvendo o esporte paraolímpico nacional e a pandemia de COVID-19 tenham adentrado este período.

No intervalo de tempo analisado, foram identificados três ciclos de veiculação de notícias, os quais possuem inter-relações quanto aos seus conteúdos. Todavia, para melhor compreendê-los, apresentamos os resultados do estudo em três eixos: a) O esporte paraolímpico brasileiro e os primeiros impactos da pandemia de COVID-19; b) Novas iniciativas para o movimento paraolímpico brasileiro: profissionais em foco e c) Representações sociais sobre deficiência e esporte em tempos de pandemia. Os três eixos compreendem o período de 16 de março a primeiro de abril de 2020, de cinco de abril a primeiro de maio de 2020 e de quatro de maio a primeiro de junho de 2020, respectivamente. Para cada um dos eixos, foram realizadas discussões amparadas na revisão de literatura sobre o tema e na perspectiva teórica das Representações Sociais. (JODELET, 2001).

\section{O ESPORTE PARAOLÍMPICO BRASILEIRO E OS PRIMEIROS IMPACTOS DA PANDEMIA DE COVID-19}

No período de 16 de março a primeiro de abril de 2020 foram publicadas seis notícias na página de imprensa do CPB. Destas, duas trataram da suspensão de atividades realizadas de forma contínua pelo CPB no Brasil, duas registraram o falecimento de um atleta e de uma atleta paralímpica(o) brasileira(o) e duas consistiram em mensagens referentes ao adiamento dos Jogos Olímpicos (JO) e dos JP de Tóquio 2020, conforme exibe o Quadro 1.

A partir das informações coletadas, nota-se que os primeiros impactos da pandemia de COVID-19 no esporte paraolímpico brasileiro envolveram a suspensão de atividades pelo CPB por tempo indeterminado. No dia 16 de março de 2020 a entidade publicou um comunicado oficial a respeito do cancelamento e da suspensão de todas as atividades realizadas no CT Paraolímpico, incluindo aquelas que estavam previstas no calendário de eventos e as sucedidas diariamente, a saber: os campeonatos, os treinamentos de clubes e seleções e; as atividades do Centro de Formação Esportiva. 


\section{Edição Especial COVID-19}

Na mesma data, foi divulgada a suspensão das atividades dos cursos do programa Educação Paralímpica, oferecidos pelo CPB em todas as regiões do Brasil. Nesta notícia, os cursos foram suspensos até o dia cinco de junho de 2020, indicando certa expectativa de sua retomada ainda no primeiro semestre do ano. Nestas primeiras notícias, envolvendo a pandemia de COVID-19, destacou-se a prioridade "com o ser humano, com a saúde, segurança e integridade da comunidade paraolímpica."

Quadro 1 - Notícias veiculadas no site do CPB de 16 de março a primeiro de abril de 2020.

\begin{tabular}{|c|c|}
\hline Assunto das notícias & Número de notícias \\
\hline Suspensão de atividades & 2 \\
\hline Nota de falecimento de atletas & 2 \\
\hline Jogos Olímpicos e Jogos Paralímpicos de Tóquio 2020 & 2 \\
\hline
\end{tabular}

Fonte: Elaborado pelas autoras.

Poucos dias após as referidas notícias, em 22 de março de 2020, foi publicada nota de pesar pelo falecimento da atleta brasileira da modalidade do tênis de mesa paraolímpico, Eliane Corrêa. O texto noticiado apontou a suspeita do contágio do vírus COVID-19 e a consequente inviabilização do ritual de velório antes do sepultamento da atleta. Reitera-se, nesse sentido, que as pessoas com deficiência enfrentam risco elevado, em comparação às demais pessoas, de contrair o coronavírus. E, quando isto ocorre, pode levá-las a graves condições de saúde. (ONU, 2020). Na notícia, além de se manifestar os pêsames do CPB aos familiares e amigos de Eliane Corrêa, foi atribuído um pequeno trecho sobre sua pessoa: "Ela era professora e apaixonada por samba, desfilando na ala inclusiva da escola Rosas de Ouro." (NOTA..., 2020). Não foram citadas informações acerca da sua trajetória no esporte e no movimento paraolímpico, exceto sua vinculação à Confederação Brasileira de Tênis de Mesa (CBTM), filiada ao CPB, e à Associação de Assistência à Criança Deficiente (AACD) de São Paulo/SP.

O início do período de divulgação dos decretos de isolamento social no Brasil coincidiu com o momento em que as discussões sobre o adiamento dos Jogos Olímpicos e dos Jogos Paralímpicos de 2020, a realizarem-se em Tóquio, no Japão, estavam aquecidas em âmbito mundial. Houve o posicionamento de diversos órgãos esportivos e a espera de atletas, treinadores, dirigentes, pesquisadores, entre outros indivíduos envolvidos com o esporte, pela decisão do Comitê Olímpico Internacional (COI) a respeito da manutenção das datas previstas para o evento ou a sua transferência. Ainda no mês de março, com a incerteza a respeito do adiamento ou não da realização dos Jogos Paralímpicos em 2020, atletas paraolímpicos brasileiros resistiram em iniciar o isolamento social, buscando locais alternativos para os seus treinos, uma vez que assim como o CT Paraolímpico, outros locais de treinamento decretaram a suspensão 
de suas atividades. Conforme relato do presidente do CPB, Mizael Conrado de Oliveira, nos primeiros dias após a suspensão das atividades do CT Paraolímpico, ocorreram situações em que dirigentes da entidade encontraram atletas do atletismo paraolímpico realizando seus treinos de forma improvisada em frente aos portões de acesso ao complexo do CT Paraolímpico. (CPB, 2020).

No dia 30 de março de 2020, o COI anunciou a sua decisão. Os Jogos Olímpicos e os Jogos Paralímpicos foram adiados. Na ocasião, publicou-se no site do CPB mensagem de apoio e concordância da entidade brasileira sobre a decisão do COI. Assinada pelo presidente do CPB, Mizael Conrado de Oliveira, a notícia foi acompanhada da seguinte mensagem direcionada aos atletas paraolímpicos brasileiros:

O mais importante é preservar a saúde, permanecer em segurança e não colocarem seus familiares em risco. Fiquem em casa e se protejam. Logo mais, as instalações do CT Paralímpico e demais equipamentos esportivos espalhados pelo mundo, assim como a sociedade brasileira, aguardam vocês e suas medalhas lá do outro lado do mundo em 2021. (MENSAGEM..., 2020).

Em seguida, foi divulgada a confirmação das novas datas definidas pelo COI, o Comitê Organizador de Tóquio 2020, o governo japonês e o IPC para os JO e os JP: de 23 de julho a oito de agosto de 2021 e de 24 de agosto a cinco de setembro de 2021, respectivamente. Nesta notícia, foi apresentado trecho de fala do presidente do IPC, Andrew Parsons: "[...] a 512 dias dos Jogos de Tóquio, a prioridade de todos integrantes do Movimento Paralímpico deve ser em manterem-se protegidos e saudáveis durante esse momento difícil e sem precedentes" (Jogos..., 2020). Segundo a matéria, assinada pela Assessoria de Comunicação do CPB, o presidente do IPC se comprometeu que "trabalhará com as federações internacionais para estabelecer novos critérios de classificação, porém, respeitando os atletas que já haviam assegurado suas vagas para os Jogos." (JOGOS..., 2020).

No primeiro dia do mês de abril, a imprensa do CPB trouxe nova notícia relativa ao falecimento de atleta paraolímpico brasileiro. Desta vez, a nota de pesar foi sobre o falecimento de Dirceu Pinto, atleta da modalidade da bocha paraolímpica vinculado à Associação Nacional de Desporto para Deficientes (ANDE) e à Associação Desportiva de Mogi das Cruzes (ADMC). Além de expressar sentimentos à família e aos amigos de Dirceu Pinto, o CPB mencionou aspectos de sua trajetória, ressaltando as conquistas do atleta paraolímpico brasileiro como as quatro medalhas de ouro conquistadas nos JP de Pequim, na China em 2008 e em Londres, na Inglaterra em 2012, nas disputas simples e em dupla. Nos JP Rio 2016, Dirceu Pinto conquistou medalha de prata na disputa em equipes. Ademais, obteve conquistas em campeonatos mundiais da modalidade. Os destaques aos títulos obtidos pelo atleta, representado na notícia como "tetracampeão paralímpico de bocha", expressam a sua importância à memória esportiva brasileira. Conforme a notícia, o seu falecimento foi causado por problemas cardíacos, não havendo relação com o vírus COVID-19.

Os primeiros impactos da pandemia de COVID-19 no esporte paraolímpico brasileiro convergiram para a mobilização de entidades à promoção de iniciativas de forma 
remota. As estratégias e ações idealizadas pelo CPB a fim de "manter ativo" o movimento paraolímpico brasileiro foram materializadas por intermédio de suas redes sociais, de plataformas virtuais, dentre outras mídias digitais. Tais iniciativas, noticiadas por meio de seu site, constam nos tópicos a seguir.

\section{NOVAS INICIATIVAS PARA O ESPORTE PARAOLÍMPICO BRASILEIRO: PROFISSIONAIS EM FOCO}

No período de cinco de abril a primeiro de maio de 2020 foram divulgadas 16 notícias no site do CPB. Após cerca de 20 dias da publicação do comunicado oficial sobre o cancelamento e a suspensão das atividades no CT Paraolímpico, o CPB divulgou, no dia cinco de abril de 2020, a série de "Lives com Profissionais da Natação Paralímpica", que ocorreu ao longo do mês em abril por meio da página oficial de Instagram da entidade. Este tema recebeu nove publicações no site investigado no período delimitado para este tópico do texto. No dia seguinte, em seis de abril, foi noticiado o lançamento do "Programa de Acompanhamento aos Atletas em Quarentena", se restringindo a esta única notícia sobre o assunto ao longo do referido mês. Ainda, no período demarcado neste tópico, foram publicadas quatro notícias relativas a suspensão de atividades e eventos do movimento paraolímpico, uma nota de repúdio à humoristas e um caso de doping de atleta paraolímpico brasileiro, conforme os dados apresentados no quadro dois.

Quadro 2 - Notícias veiculadas no site do CPB de cinco de abril a primeiro de maio de 2020.

\begin{tabular}{|c|c|}
\hline Assunto das notícias & Número de notícias \\
\hline Lives com Profissionais da Natação Paralímpica & 9 \\
\hline $\begin{array}{c}\text { Programa de Acompanhamento } \\
\text { aos Atletas em Quarentena }\end{array}$ & 1 \\
\hline Suspensão de atividades e eventos & 4 \\
\hline Nota de repúdio a humoristas & 1 \\
\hline Doping de atleta paralímpico brasileiro & 1 \\
\hline
\end{tabular}

Fonte: Elaborado pelas autoras.

As notícias de divulgação das "Lives com Profissionais da Natação Paralímpica" mantiveram o mesmo padrão ao longo do mês de abril, sendo publicadas com antecedência de um dia da sua transmissão, com informações a respeito do tema a ser abordado e do profissional a falar sobre o assunto, sendo apresentados aspectos de sua formação acadêmica e de sua atuação profissional na respectiva área. A cada divulgação, os links para acesso às lives já sucedidas foram disponibilizados. O tema 
de cada live e o nome do profissional responsável por abordar o assunto é apresentado no quadro três.

Quadro 3 - Lives do CPB com profissionais da Natação Paralímpica no mês de abril de 2020.

\begin{tabular}{|c|c|c|}
\hline Assunto das Lives & Profissional & Área de formação* \\
\hline Preparação para os Jogos de Tóquio & Não citado & Não citada \\
\hline Fisioterapia & Everton Araújo & Fisioterapia \\
\hline Ciência do Esporte & Augusto Barbosa & Educação Física \\
\hline Fisioterapia aplicada aos atletas & Rafael Martins & Fisioterapia \\
\hline Preparação física & Henrique Oliveira & Educação Física \\
\hline $\begin{array}{l}\text { Nutrição direcionada aos praticantes da } \\
\text { modalidade }\end{array}$ & Alan Nagaoka & $\begin{array}{l}\text { Bases Nutricionais da } \\
\text { atividade física }\end{array}$ \\
\hline $\begin{array}{c}\text { Treinamento para os atletas de classes } \\
\text { baixas }\end{array}$ & Fabiano Quirino & Fisiologia do Exercício \\
\hline Evolução da Medicina Esportiva & Hésojy Gley & Medicina \\
\hline Psicologia Esportiva & Fabrizio Veloso & Neuropsicologia \\
\hline
\end{tabular}

Legenda: * - Área de formação descrita na apresentação dos profissionais nas notícias de divulgação das lives.

Fonte: Elaborado pelas autoras.

Afora as lives, no início do mês de abril foi publicada notícia sobre o lançamento do "Programa de Acompanhamento aos Atletas em Quarentena". Conforme a notícia, a partir do momento em que o CT Paraolímpico teve suas atividades suspensas, com o comunicado oficial de 16 de março, os atletas paraolímpicos que treinavam neste local foram "embarcados de volta às suas respectivas cidades e seguiram uma rotina de treino temporária, apenas com orientações dos técnicos e sem um programa sistematizado de atividades e de acompanhamento." (CPB LANÇA..., 2020). Nessa direção, a implantação do referido programa pelo CPB, noticiado no dia seis de abril de 2020, buscou orientar os atletas a estabelecer uma rotina de atividades de treinamento durante o período de isolamento social, com o apoio da equipe multidisciplinar do CPB, incluindo fisiologistas, preparadores físicos, nutricionistas, treinadores e psicólogos. A atividade ocorria por intermédio de videochamadas entre os profissionais e os atletas de forma individualizada ou em pequenos grupos, conforme cada caso. 
Na notícia ainda se ressaltou que o objetivo do programa é "controlar os efeitos do destreinamento (perda de condicionamento) dos atletas enquanto os locais de treino estiverem indisponíveis", pois de acordo com o diretor técnico do CPB, Alberto Martins, "Neste momento [de pandemia], o ganho de peso é a nossa maior preocupação em relação aos atletas." (CPB LANÇA..., 2020). Ressaltou, ainda, que o programa busca evitar que os atletas realizem treinos sem orientação a fim de "prevenir lesões e permitir que eles retornem, após a pandemia, com as condições físicas e mentais próximas ao ideal." (CPB LANÇA..., 2020). A notícia também divulgou os relatos de Verônica Hipólito, atleta do atletismo paraolímpico, e de Matheus Reine, atleta da natação paraolímpica, que expressaram apoio à iniciativa do CPB: "haverá atividades exclusivas para atletas que moram na cidade, no interior e no litoral. [...] para quem mora em apartamento ou casa. [...] este acompanhamento contribuirá bastante para que nos mantenhamos em atividade e mais tranquilos com a nossa preparação", apontou Verônica Hipólito. E, complementou Matheus Reine: "Essa iniciativa do atleta poder treinar em casa, com os exercícios pré-elaborados com o conhecimento específico para cada situação, será muito importante para este momento e até para o restante das nossas vidas." (CPB LANÇA, 2020).

O Programa de Acompanhamento aos Atletas em Quarentena, em um primeiro momento, contemplaria cerca de 80 atletas do atletismo paraolímpico e da natação paraolímpica, ambas modalidades administradas de forma direta pelo CPB, que atua como confederação para estes dois esportes. Posteriormente, a ideia seria levar o programa às confederações responsáveis pelas demais modalidades paraolímpicas do país, a fim de auxiliar o treinamento de todos os atletas da seleção paraolímpica brasileira durante o isolamento. Ao longo do período investigado neste estudo, não foram publicadas novas notícias de forma específica sobre os desdobramentos deste programa. Todavia, aspectos dos treinamentos dos atletas durante o período de pandemia passaram a ser abordados nas lives promovidas no mês de maio, conforme se apresenta no tópico seguinte deste texto.

No período de cinco de abril a primeiro de maio de 2020, no site CPB também se divulgou o cancelamento e a suspensão de quatro eventos. A primeira destas notícias ocorreu em nove de abril de 2020, com o cancelamento das Paralimpíadas Universitárias 2020, evento agendado para o período de 23 a 25 de julho deste ano. A competição, que conta com a participação de estudantes universitários com deficiência, acontecendo anualmente desde 2016, terá a sua próxima edição redefinida após o retorno das atividades esportivas no Brasil. No dia 17 de abril de 2020, foi anunciada a suspensão da Escola de Esportes Paralímpicos do CPB até o ano de 2021. Este projeto desenvolve atividades de iniciação esportiva às crianças e jovens com deficiência na faixa etária de oito a 17 anos de idade, desde o ano de 2018, no CT Paraolímpico. O presidente do CPB, Mizael Conrado de Oliveira, afirmou que o projeto Escola de Esportes Paralímpicos não foi encerrado, apenas está impossibilitado de ter suas atividades retomadas no ano corrente, sobretudo, considerando o dever da entidade em assegurar a integridade de seus alunos. Na data de 22 de abril de 2020, mais um evento agendado para o ano de 2020 foi cancelado, 
sendo este o Festival Paralímpico, ação idealizada pelo CPB no ano de 2018 a fim de se comemorar o Dia do Atleta Paralímpico (22 de setembro) com a realização de oficinas de modalidades paraolímpicas em cidades de todos os estados brasileiros. (BATAGLION; MAZO, 2019). O evento deste ano estava agendado para o dia 19 de setembro de 2020.

Além dos projetos e eventos de âmbito nacional, foi noticiada no site do CPB, em 30 de abril de 2020, a transferência da décima edição do Campeonato Mundial de Atletismo que ocorreria nos dias 17 e 26 de setembro de 2021 para as datas de 26 de agosto a quatro de setembro de 2022, preservando a sua realização em Kobe, no Japão. A decisão foi tomada pelo Comitê Organizador da competição, após acordo com o IPC e com a Associação Mundial de Atletas Paralímpicos (WPA), a fim de se evitar o conflito de datas com os Jogos Paralímpicos de Tóquio.

$\mathrm{Na}$ data de 13 de abril de 2020, foi publicada a seguinte notícia, assinada pelo presidente do CPB, Mizael Conrado de Oliveira: “CPB protocola denúncia contra "humoristas"; Leia nota". Sob este título, a publicação tratou de denúncia protocolada pelo CPB junto ao Ministério Público Estadual de São Paulo contra os comediantes Abner Henrique e Dihh Lopes. Este movimento, engendrado pelo CPB, contou com o apoio de entidades que compõem o Sistema Nacional de Esporte e representantes do poder legislativo, congregando 36 subscrições para tal nota. A denúncia apontou que os comediantes teriam cometido, em seus shows de comédia - republicados em redes sociais -, o crime de capacitismo - "aquele no qual um indivíduo age de forma preconceituosa e discriminatória contra a pessoa com deficiência." (CPB PROTOCOLA..., 2020). Crime este, descrito na Lei n. 13.146/2015 - Lei Brasileira da Inclusão, também conhecida como Estatuto da Pessoa com Deficiência. (BRASIL, 2015).

Nesta notícia, acompanhada por uma imagem com a representação de nota de repúdio, o CPB reiterou a sua "mais completa indignação e repúdio aos pretensos comediantes Abner Henrique e Dihh Lopes pelo modo ofensivo, ultrajante e desumano como trataram as pessoas com deficiência em seus shows", nos quais, continua a nota "[...] a dupla debulha um rosário de preconceitos contra os amputados, autistas, acometidos por síndrome de Down e crianças com câncer, utilizando-se do subterfúgio de fazer comédia." (CPB PROTOCOLA..., 2020). Aludindo o ocorrido como um "verdadeiro show de horrores", Mizael Conrado de Oliveira lamentou que os discursos dos comediantes tivessem contado com aplausos e risadas por parte do público espectador.

Atenta-se, assim, para os referidos shows de comédia enquanto um espaço de reprodução de discursos, influenciando processos de construção e multiplicação de práticas e de representações sociais que incitam a intolerância às diferenças. (HILLESHEIM; CAPPELLARI, 2019). Assim, conforme as autoras (2019), a mídia pode tanto exercer a função de defender e de proliferar valores da inclusão como da exclusão, produzindo modos de ser e de estar no mundo. Práticas discursivas, como aquelas identificadas no "show de humor", atuam na construção de imaginários 
sociais que passam a ser compartilhados coletivamente no interior dos grupos de pertença. (JODELET, 2001). Nesse sentido, diversas práticas e representações estigmatizantes, imbricadas historicamente na sociedade, geram contextos de exclusão em que muitas pessoas com deficiência se encontram fragilizadas para lutar pelos próprios direitos, assegurados pela legislação. (BRASIL, 2015; MENDONÇA, et al. 2020). De tal modo, o papel de entidades como o CPB é essencial na tomada de decisões e no posicionamento frente às injustiças sociais que atingem a população com deficiência, bem como na defesa de seus direitos, não apenas no esporte, mas em toda e qualquer atividade humana.

No período investigado para este tópico, ainda foi noticiada a desclassificação do atleta brasileiro de ciclismo paraolímpico, Soelito Gohr, dos Jogos Parapan-Americanos de Lima 2019 após o IPC divulgar que o resultado de seu exame de urina apresentou substância proibida pela Agência Mundial Antidoping (WADA). Vale mencionar que o IPC possui um Código Antidoping próprio para prevenir o doping no esporte paraolímpico e que suas normas estão em conformidade com os mesmos princípios da WADA. Além da referida desclassificação determinada pelo IPC, a Associação Internacional de Ciclismo, é o órgão responsável por determinar a pena ao ciclista, o que poderá englobar a exclusão de qualquer medalha, ponto ou premiação obtida pelo atleta no período.

\section{REPRESENTAÇÕES SOCIAIS SOBRE DEFICIÊNCIA E ESPORTE EM TEMPOS DE PANDEMIA}

No período de quatro de maio a primeiro de junho de 2020 foram publicadas 26 notícias na página de imprensa do CPB. Destas, 18 foram dedicadas a divulgar e a comentar/registrar as lives promovidas pelo CPB em sua mídia social, o Instagram @ocpboficial. Além disso, no espaço temporal arrolado neste tópico do texto, oito outros assuntos foram noticiados com uma ocorrência para cada, conforme especificações no Quadro 4.

No que tange as lives promovidas pelo CPB a partir do mês de maio, destacamos que ocorreram 18 notícias, sendo 11 referentes à Live Paralímpica e sete à Live \#Tamo Junto. Em geral, cada uma delas contou com duas notícias, sendo a primeira dedicada a divulgar a data e o horário de cada live, incluindo os participantes e o assunto/modalidade a ser abordado. Já, a segunda notícia, contemplou informações que emergiram dos debates/entrevistas que foram transmitidos ao vivo no Instagram @ocpboficial.

A série Live Paralímpica foi destinada a transmitir entrevistas realizadas com atletas paraolímpicos brasileiros. Foram entrevistados cinco atletas no mês de maio de 2020, conforme o quadro cinco. No mês de junho, a série de lives teve continuidade, havendo uma notícia no primeiro dia deste mês, com a divulgação de live com o atleta de Rodolpho Riskalla e com a programação completa do mês. Por sua vez, a série Live \#Tamo Junto consistiu em uma parceria realizada entre o CPB e o Comitê Olímpico Brasileiro (COB) a fim de promoverem debates entre atletas paraolímpicos e olímpicos 
sobre as suas modalidades, sendo transmitidos ao vivo nas páginas de Instagram @ocpboficial e @timebrasil. Foram realizadas três lives desta série no mês de maio, de acordo com o quadro cinco, tendo sequência no mês de junho.

Quadro 4 - Notícias veiculadas no site do CPB de quatro de maio a primeiro de junho de 2020.

\begin{tabular}{|c|c|}
\hline Assunto das notícias & Número de notícias \\
\hline Lives & 18 \\
\hline Doping de atleta paralímpica brasileira & 1 \\
\hline Regulamento dos Jogos Paralímpicos de Tóquio & 1 \\
\hline Eleições do Conselho de Atletas & 1 \\
\hline Carreira de atleta paralímpico brasileiro de hipismo & 1 \\
\hline Podcast Papo Paralímpico & 1 \\
\hline Atletas com deficiência visual durante a pandemia & 1 \\
\hline Lançamento da plataforma “Movimente-se” & 1 \\
\hline Cancelamento de evento & \\
\hline
\end{tabular}

Fonte: Elaborado pelas autoras.

No âmbito das modalidades paraolímpicas, é possível observar que o conjunto de lives comportou a abordagem de sete modalidades praticadas e disputadas por atletas com variados tipos de deficiência física (Atletismo paraolímpico, Para taekwondo, Bocha paraolímpica, Para badminton, Tênis de mesa paraolímpico e Voleibol sentado) e de uma modalidade específica para atletas com deficiência visual (Judô paraolímpico). Os atletas que participaram de cada uma das séries de lives estão apresentados no quadro cinco, seguidos pelas suas devidas modalidades.

As notícias veiculadas acerca das lives no site do CPB abrigaram os seguintes temas: histórias de vida, tratando de aspectos sobre como os(as) atletas paraolímpicos(as) supracitados(as) adquiriram as suas deficiências (quando adquirida) e como ingressaram no esporte paraolímpico; as conquistas dos(as) atletas paraolímpicos(as) em competições esportivas e em prêmios como o "Prêmio Paralímpicos"; os treinos dos(as) atletas paraolímpicos(as) durante o isolamento e; relatos dos(as) atletas paraolímpicos(as) a respeito de suas modalidades, estabelecendo comparações com as modalidades olímpicas, no caso das lives da série \#Tamo Junto. 
Quadro 5 - Séries de Lives do CPB no período de quatro de maio a primeiro de junho de 2020.

\begin{tabular}{|c|c|c|}
\hline Série da Live & Atletas & Modalidades \\
\hline \multirow{2}{*}{ Live Paralímpica } & Petrúcio Ferreira & Atletismo paraolímpico \\
& Débora Menezes & Para taekwondo \\
& Alana Maldonado & Judô paraolímpico \\
& Evani Calado & Bocha paraolímpica \\
& Vitor Tavares & Para badminton \\
& Rodolpho Riskalla & Hipismo paraolímpico \\
\hline \multirow{2}{*}{ Live \#Tamo Junto } & Petrúcio Ferreira & Atletismo paraolímpico \\
& Alison Brendom & Atletismo olímpico \\
& Paulo Salmin & Tênis de mesa paraolímpico \\
& Bruna Takahashi & Tênis de mesa olímpico \\
& Edwarda Dias & Voleibol sentado \\
& Ricardo Santos & Vôlei de praia \\
\hline
\end{tabular}

Fonte: Elaborado pelas autoras.

Vale pontuar que, no que se refere aos(às) atletas paraolímpicos(as), ocorreram o mesmo número de lives com a presença feminina (quatro) e masculina (quatro) no período abordado neste tópico. Embora nenhuma das lives tenha se dedicado a tratar o tema das mulheres no esporte paraolímpico de forma específica, nota-se que ele emergiu nos momentos de entrevista, como na fala de Débora Menezes, divulgada em notícia:

Quando jogava futsal ouvia muito que não era lugar de mulher, que era para ir limpar a casa. Sempre me posicionei firme contra esse tipo de atitude. Lugar de mulher é onde ela quiser! Quando comecei na luta já tinha isso tão claro dentro de mim que não me abalava mais e com todo o apoio da comissão técnica pude mostrar quem eu sou." (LIVE..., 2020a).

A fala da atleta do Para taekwondo denota que, para além das barreiras atreladas à deficiência, as mulheres do esporte paraolímpico podem enfrentar preconceitos relativos ao sexo. (SANCHOTENE et al., 2020). No caso desta atleta, nota-se a importância da autoconfiança, da determinação e da equipe profissional para ela seguir na carreira esportiva. Igualmente, observa-se a abertura de espaço na mídia investigada para não apenas se vangloriar as excelências atléticas das mulheres com 


\section{Edição Especial COVID-19}

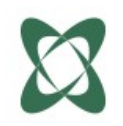

deficiência no esporte, mas, também, para se debater questões acerca de enfrentamentos para o seu ingresso e para a construção de suas carreiras no esporte paraolímpico. Neste cenário, conforme Haiachi et al. (2018), através do empoderamento, a mulher constrói sua nova identidade, a de atleta paraolímpica.

Faz-se relevante pontuar que Débora Menezes praticou outros esportes antes de ingressar no Para taekwondo como o futsal, o lançamento de dardo, e o boxe. Ao boxe, a atleta teve acesso na universidade, enquanto cursava Educação Física, posteriormente conheceu o Para taekwondo: “Comecei a praticar a modalidade como hobbie, não pensava em competir. Mas depois que ela entrou no programa dos Jogos, em 2015, eu vi a chance de chegar a tão sonhada Seleção e aos Jogos Paralímpicos." (LIVE..., 2020a). Isto reforça a importância da garantia ao acesso das pessoas com deficiência à universidade, bem como a relevância dos projetos esportivos abertos a esta população. Evani Calado também relatou ter desfrutado da oportunidade de receber convite à prática de bocha paraolímpica enquanto cursava graduação em Publicidade e Propaganda. Em sua entrevista, a atleta recordou, em especial, da importância da inserção no esporte ainda na fase escolar, destacando o olhar inclusivo de um professor de Educação Física:

Ele levou um cano de PVC e bolinhas de tênis para aula e foi assim que joguei bocha pela primeira vez, de forma adaptada, claro. [...] Eu ficava na sala durante as aulas de Educação Física na escola, mas esse professor me fez sair de lá. Ele se importou e estava disposto a me incluir na aula. Atitudes assim fazem toda diferença." (LIVE..., 2020b).

Acredita-se que cada vez mais iniciativas inclusivas são promovidas por professores de Educação Física nas escolas brasileiras. Os variados projetos de viés escolar fomentados pelo CPB em nível nacional contribuem para o desenvolvimento de cenário favorável à inclusão de estudantes com deficiência, do ensino básico e superior, por meio do esporte. (BATAGLION; MAZO, 2019). Todavia, vale mencionar a relevância de que tais ações convirjam para a contemplação do esporte paraolímpico escolar em projetos e, principalmente, em políticas públicas de esporte nos contextos estaduais e municipais. (BATAGLION; MAZO, 2019).

Os projetos escolares do CPB, suspensos durante a pandemia de COVID-19, oportunizam a inserção de crianças e jovens com deficiência no esporte. Diversos destes já alcançaram alto nível de desempenho, avançando da prática de nível escolar para a carreira de alto rendimento no esporte paraolímpico. Isto permite que a renovação dos(as) atletas paraolímpicos(as) brasileiros(as) ocorra de forma sistematizada. O atleta de atletismo paraolímpico, Petrúcio Ferreira, por exemplo, é um dos atletas "revelados" pelas "Paralimpíadas Escolares", competição nacional idealizada pelo CPB no ano de 2006 e que ao longo de suas edições já gerou muitos frutos ao movimento paraolímpico brasileiro. (BATAGLION et al., 2019). 


\section{Edição Especial COVID-19}

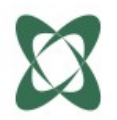

As excelências atléticas de atletas paraolímpicos culminam em uma maior publicização de suas imagens e carreiras nas mídias. (CASTRO et al., 2016). Foi o caso do atleta Petrúcio Ferreira, enfocado em cinco notícias no site no CPB no ínterim deste tópico. Dentre outros aspectos, foram destacadas conquistas do atleta em grandes competições do esporte paraolímpico, sendo evidenciado como o atual atleta paraolímpico mais rápido do mundo, com o recorde mundial de 10s42, obtido em prova de $100 \mathrm{~m}$, no Campeonato Mundial de Atletismo realizado em Dubai (Emirados Árabes Unidos) no ano de 2019. Ademais, foi ressaltada a conquista de melhor atleta do ano de 2019 no "Prêmio Paralímpicos", além do troféu de melhor atleta do atletismo paraolímpico brasileiro, acumulando quatro anos consecutivos de conquista deste prêmio. Nota-se que a obtenção de destaque no desempenho de atletas de alto rendimento do esporte paraolímpico gera seu reconhecimento em seu grupo de pertença, bem como à construção do imaginário social acerca dos ídolos paraolímpicos aos pares com e sem deficiência. As notícias veiculadas nas mídias de comunicação influenciam em grande medida para isto. (CARDOSO et al., 2018). Nesta perspectiva, o crescimento do movimento paraolímpico brasileiro nas últimas décadas e a transformação do país em uma potência paraolímpica mundial traz consigo a necessidade do desenvolvimento de projetos que visem, também, garantir a qualidade do pós-carreira do(a) atleta paraolímpico(a). Para Castro et al. (2016), esta é uma tarefa que envolve, em grande medida, o papel das variadas entidades que administram as modalidades paraolímpicas e seus(uas) atletas de alto rendimento no Brasil.

Afora as 18 notícias relativas às duas séries de lives, no período delimitado para este estudo, foram publicizadas oito notícias com uma ocorrência cada. Em cinco de maio de 2020 divulgou-se a notícia referente ao doping da atleta brasileira de natação paraolímpica Patricia Pereira dos Santos. A atleta recebeu do IPC a suspensão de sua participação em competições por um ano porque em uma amostra de urina coletada, enquanto a atleta competia nos Jogos Parapan-Americanos de Lima em 2019, foram identificadas substâncias proibidas pela WADA à sua classe de competição. Além da suspensão, a atleta perdeu as medalhas de prata e de bronze que havia conquistado no referido evento esportivo.

Na data de seis de maio de 2020, foi publicada notícia sobre os novos regulamentos de classificação para 11 das 22 modalidades do programa dos JP de Tóquio 2020, conforme critérios que são definidos pelo IPC. Mudanças foram aplicadas aos critérios de classificação de atletas para integrar as delegações nacionais em decorrência do adiamento das competições classificatórias durante a pandemia de COVID-19 no mundo. É de 4.400 o número total de vagas para atletas nesta edição dos JP. Conforme a notícia divulgada, o Brasil já possui atletas classificados(as) para 14 modalidades paraolímpicas. Assim, ao retorno das competições classificatórias, possivelmente, o país disputará vagas para outras modalidades. Ainda no dia seis de maio de 2020, foi noticiado o adiamento da eleição do Conselho de Atletas do IPC. Os seis atletas do conselho em vigor permanecerão no mandato até a próxima eleição, que ficou definida para ocorrer nos JP de Tóquio, em 2021. O processo de indicação ocorrerá no 


\section{Edição Especial COVID-19}

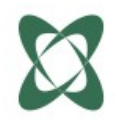

início do referido ano. A eleição para presidente do Conselho de Atletas do IPC, que ocorreria em março de 2021, foi transferida para o mês de novembro do mesmo ano, para quando está prevista a primeira reunião do novo conselho.

Em 13 de maio de 2020, com informações da Federação Internacional de Hipismo (FEI), foi publicada no site do CPB a notícia intitulada "Federação Internacional de Hipismo" destaca carreira do brasileiro Rodolpho Riskalla". Atleta de hipismo paraolímpico, Rodolpho Riskalla reside, atualmente, em Paris, na França, onde trabalha como gerente de eventos da casa de moda Paris Christian Dior. Em extensa matéria publicada, foram apresentadas informações acerca da trajetória do atleta, que até o ano de 2015 participava de campeonatos do hipismo convencional, tendo conquistado uma série de resultados expressivos. Foi destacada a tradição familiar com relação ao hipismo, sendo citado o nome da mãe de Rodolpho, Rosangele, como treinadora de adestramento. No ano de 2015, Rodolpho contraiu meningite bacteriana; recordou o atleta: “Em junho, eu competia no CDI2 em Compiegne e perseguia um sonho olímpico. Em outubro, havia perdido os dois pés, todos os dedos da mão direita e alguns da esquerda." (FEDERAÇÃO..., 2020). Ainda durante o período de reabilitação, realizada na França, Rodolpho iniciou a transição para o hipismo paraolímpico e, um ano após ter adquirido deficiência, já participava dos JP Rio 2016, conquistando o décimo lugar em prova individual. A matéria também referiu informações sobre Don Henrico e Don Frederic, nomes dos cavalos que acompanham o atleta nas competições paraolímpicas. No esporte, os cavalos são considerados, também, competidores, havendo forte relação de interação entre ambos (atleta e cavalo). Por fim, se ressaltou a diferenciada capacidade de adaptabilidade apresentada por Rodolpho Riskalla, dada a sua trajetória. O percurso esportivo do atleta voltou a ser noticiado em primeiro de junho, com a divulgação de sua participação na primeira Live Paralímpica do mês de junho.

A notícia de 18 de maio de 2020 se dedicou a divulgar os episódios do podcast oficial do CPB, denominado "Papo Paralímpico". Nesta data, foi colocado no ar o episódio sete, intitulado "Esporte Paralímpico em tempos de pandemia", o qual teve como apresentador o presidente do CPB, Mizael Conrado de Oliveira e como convidados o jornalista esportivo do grupo Globo, Renato Peters, o gerente de comunicação do CPB, Daniel Brito, e o diretor de operações do CT Paraolímpico, Marcos Garcia. Este foi o primeiro episódio realizado após o comunicado oficial de suspensão das atividades do CT Paraolímpico, assunto que foi foco do debate entre o apresentador e os convidados, trazendo informações a respeito do cenário do esporte paraolímpico brasileiro diante do isolamento social. Ademais, foi realizada homenagem ao atleta de bocha paraolímpica Dirceu Pinto, que faleceu no mês de março.

As lives realizadas entre quatro de maio e primeiro de junho de 2020 pelo CPB tiveram, predominantemente, participantes/entrevistados(as) de modalidades para atletas com deficiências físicas. Como é possível observar no quadro cinco, Alana Maldonado, do judô paraolímpico, foi a única atleta com deficiência visual entrevistada. Por outro lado, na data de 29 de maio de 2020, no site da entidade nacional foi publicado texto da Confederação Brasileira de Desporto de Deficientes 


\section{Edição Especial COVID-19}

Visuais (CBDV), entidade responsável pelas modalidades do Futebol de cinco, Goalball e Judô Paraolímpico no Brasil. Intitulada "Tecnologia ajuda cegos a se manterem ativos na quarentena", a notícia buscou retratar a forma como os(as) atletas paraolímpicos(as) brasileiros(as) das três referidas modalidades realizam seus treinos durante a pandemia do coronavírus. Conforme indica o título veiculado, o uso de recursos digitais como grupos de Whatsapp e a plataforma Zoom foram citados como estratégias utilizadas para se viabilizar algumas atividades, todavia se destacou que as perdas físicas e técnicas são inevitáveis aos(às) atletas destas modalidades.

Na matéria, foram citadas falas de técnicos(as) e gestores(as) de distintas entidades do país. Rafael Astrada (da Associação Gaúcha de Futebol para Cegos - AGAFUC/RS), Fábio Costa e Renata Pozzi (ambos da Associação Maestro da Bola/PR), relataram o envio de exercícios por meio de áudio e vídeo aos(às) atletas, com posteriores reuniões de vídeo para melhorar o entendimento das instruções técnicas e verificar a realização dos treinos por parte dos(as) atletas de equipes do Futebol de cinco. No caso do Goalball, Diego Valadares (Associação dos Deficientes Visuais de Belo Horizonte - Adevibel/MG) e Gabriel Goulart (Associação de Centro de Treinamento de Educação Física Especial - Cetefe/DF) citaram o uso destes mesmos recursos e estratégias, acrescentando o uso do mapeamento dos espaços que cada atleta dispõe em suas residências, a fim de elaborem treinos viáveis de execução. Já, Diego Colletes, das equipes, masculina e feminina, de Goalball do Serviço Social da Indústria de São Paulo (SESI/SP), relatou que após ter seguido os referidos formatos de treino durante os meses de março e abril, em maio retomou os trabalhos presenciais, em Suzano/SP, com parte de ambas as equipes, seguindo os protocolos de segurança necessários. Sobre a modalidade do Judô Paraolímpico, os depoimentos foram dos(as) atletas Roberto Paixão e Maria Núbea Lins, que referiram as dificuldades para treinar, especialmente para aplicar golpes sem um oponente. Nesse sentido, mencionaram o apoio dos cônjuges para a realização de treinos improvisados em casa.

Em primeiro de junho de 2020, foi noticiado o cancelamento das Paralimpíadas Escolares 2020, a 14a edição do evento estava prevista para acontecer no período de 23 a 28 de novembro. A decisão pelo cancelamento da competição sucedeu de forma tardia, se comparada a divulgação do cancelamento de outros eventos e projetos do CPB em decorrência da pandemia de COVID-19. As Paralimpíadas Escolares representam ampla relevância para o movimento paraolímpico brasileiro, tanto no âmbito dos impactos na renovação das equipes de alto rendimento, como na disseminação das modalidades paraolímpicas pelo país e na inclusão de crianças e jovens com deficiência por meio do esporte. (BATAGLION; MAZO, 2019). De tal modo, acredita-se que a equipe organizadora possuísse expectativa quanto à manutenção de sua realização nas datas previamente agendadas. Entretanto, com o desenrolar e a amplitude dos problemas oriundos da pandemia, não se tinha alternativa, a não ser o cancelamento deste importante evento escolar, até mesmo considerando o prolongamento da interrupção dos calendários escolares de ensino fundamental e médio e o cancelamento de diversas competições seletivas estaduais que são requisito à composição das delegações para participarem nas Paralimpíadas Escolares. 
Também no primeiro dia do mês de junho, divulgou-se o lançamento da plataforma "Movimente-se", noticiada como a primeira plataforma digital de atividade física para pessoas com deficiência. Idealizado pelo CPB, o programa tem a intenção de levar orientações profissionais às pessoas com deficiência física e visual para a prática de exercícios físicos. As videoaulas do programa, gravadas de forma direcionada para cada tipo de deficiência, contam com a orientação de treinadores do CPB e com a demonstração dos exercícios por parte de atletas paraolímpicos(as) brasileiros(as). As aulas são compostas por aquecimento, parte principal e volta à calma, sendo disponibilizadas no canal de YouTube do CPB e em site específico do programa (disponível em: <http://www.movimentoparalimpico.com.br $>$ ). As videoaulas para pessoas com deficiência visual contam com recursos de comunicação acessível. Conforme o presidente Mizael Conrado de Oliveira, a criação do Movimente-se visa garantir ações de inclusão da pessoa com deficiência - uma das missões do CPB - em tempos de isolamento social. Iniciativa esta providencial e de extrema relevância, tendo em vista o esquecimento acerca da pessoa com deficiência - grupo de risco por variadas frentes de ação em tempos de pandemia.

Por fim, cabe mencionar que a crise global resultante da pandemia de COVID-19 intensificou as desigualdades e evidenciou representações sociais de exclusão, preconceito e discriminação ainda existentes acerca da pessoa com deficiência na sociedade. Visando garantir a integração e assegurar os direitos das pessoas com deficiência nas políticas e ações de resposta e de recuperação à crise, a ONU elaborou o documento intitulado "COVID-19 - Respostas inclusivas para as pessoas com deficiência." (ONU, 2020). Em contexto sem pandemia, sabe-se que o acesso desta população à informação, instalações, serviços e programas já se apresenta reduzido e/ ou dificultado quando comparados aos seus pares sem deficiência. De tal modo, atentar-se para estes aspectos em tempos de coronavírus é fundamental a fim de que as pessoas com deficiência não sejam deixadas à margem da sociedade neste delicado momento. Destaca-se que a ONU (2020) indica que as pessoas com deficiência sejam colocadas no centro das respostas ao COVID-19, participando como agentes de planejamento e implementação de políticas e ações. Acredita-se que o documento divulgado pela ONU no mês de maio de 2020 poderá contribuir para o planejamento e a continuidade dos programas e ações desenvolvidos pelas entidades do esporte paraolímpico, proporcionando estratégias ainda mais inclusivas e eficientes em longo prazo. Neste processo, as mídias digitais terão um papel ainda mais relevante na transmissão de notícias e informações e para a construção e a modificação das representações sociais sobre a pessoa com deficiência e o esporte paraolímpico.

\section{CONSIDERAÇÕES FINAIS}

Este estudo buscou averiguar as representações sociais acerca do esporte paraolímpico nacional diante da pandemia de COVID-19 nas notícias veiculadas pelo site do Comitê Paralímpico Brasileiro. No período de 16 de março ao dia primeiro de junho de 2020 foram publicizadas 48 notícias no site da entidade, sendo quatro 
assinadas pelo presidente do CPB, Mizael Conrado de Oliveira, e 44 pela Assessoria de Comunicação do CPB. Destas, duas atribuíram créditos ao IPC, uma à FEl e uma à CBDV. Desde o comunicado oficial de suspensão das atividades presenciais no CT Paraolímpico, em 16 de março, cinco ações de caráter remoto foram idealizadas pelo CPB, são elas: "Lives com Profissionais da Natação Paralímpica", "Programa de Acompanhamento aos Atletas em Quarentena", "Live Paralímpica", "Live \#Tamo Junto", "Programa Movimente-se". O lançamento destas iniciativas foi distribuído entre o início dos meses de abril, maio e junho.

No que condiz às notícias veiculadas no período investigado, notou-se amplo espaço conferido às séries de lives, que ocuparam 27 das 48 publicações realizadas no período investigado. No mês de abril o foco das ações foi pautado na atuação de profissionais do CPB, já, no mês de maio, tais ações convergiram para os(as) atletas paraolímpicos(as) brasileiros(as), havendo a aproximação com atletas olímpicos(as) por intermédio de parceria entre o CPB e o COB na série \#Tamo Junto. Vale referir que, se no âmbito dos(as) atletas paraolímpicos(as) observou-se a igualdade de espaço conferido aos homens e às mulheres contemplados nas lives, no que se refere aos profissionais, não foi identificada nenhuma entrevista com pessoas do sexo feminino, denotando, talvez, a supremacia masculina na equipe multidisciplinar da entidade do esporte paraolímpico nacional.

As pessoas com deficiência representam um grupo de risco que enfrenta uma invisibilidade política e social, ainda maior, durante o período de pandemia. Iniciativas como as citadas neste estudo contribuem para se auxiliar esta parcela da população, tanto atletas quanto não atletas, a manterem um isolamento social saudável, atentando para cuidados relativos ao seu bem-estar físico-motor e, em grande medida, à sua estabilidade emocional. As ações abrem espaço, ainda, para a continuidade do crescimento do número de adeptos ao esporte paraolímpico no Brasil, na medida em que tais mecanismos já vinham sendo utilizados de formas não remotas, principalmente, ante o início dos decretos de isolamento social.

Assim como as demais esferas sociais, o movimento paraolímpico brasileiro vive a incerteza com relação ao futuro. No que tange ao retorno dos treinamentos e das competições esportivas, tem-se que ocorrerá de forma muito ponderada e de acordo com as especificidades de cada modalidade paraolímpica. Observamos, por exemplo, que as equipes de Goalball do SESI/SP retomaram parte de suas atividades no mês de maio, atendendo aos protocolos necessários à saúde dos envolvidos. Entretanto, sabese que o retorno de forma segura também depende da estrutura de que dispõe cada entidade. Ademais, entende-se que algumas modalidades, sobretudo as coletivas que são praticadas e disputadas em cadeiras de rodas (CR), como o basquete em CR, o tênis em $C R$ e o rugby em $C R$, poderão ter, ainda, as implicações atreladas as evidências do maior tempo de permanência do vírus COVID-19 em materiais de metal.

Este estudo se restringiu a coleta e a análise de informações exclusivamente do site do CPB, limitando a abordagem das notícias e representações oriundas de uma única mídia digital. Todavia, vale referir que diversas outras entidades responsáveis e 
ligadas ao movimento paraolímpico brasileiro reconfiguraram suas ações e notícias em decorrência da pandemia e do isolamento social. Assim, novos estudos sobre o assunto, diversificando o uso de fontes, se fazem relevantes com vistas a ampliar os olhares às representações sociais acerca do esporte paraolímpico brasileiro nos ensejos da pandemia de COVID-19. De tal modo, este debate não se encerra aqui.

\section{REFERÊNCIAS}

BATAGLION, G. A. et al. A social representation of the disabled person in the paralympic universe: from students to athletes. In: OLIVEIRA, A. F. S. de; HAIACHI, M. de C. (Orgs.). The future of the olympic and paralympic games: 5 th Debate Cycle in Olympic and Paralympic Studies. Florianópolis: Tribo da Ilha, 2019. p.195-223.

BATAGLION, G. A.; MAZO, J. Z. Paralimpíadas escolares (2006-2018): evidências em mídias digitais acerca do evento esportivo. Recorde - Revista de História do Esporte, v.12, n.1, p.1-42, 2019.

BRASIL. Lei no 13.146, de 6 de julho de 2015. Institui a Lei Brasileira de Inclusão da Pessoa com Deficiência (Estatuto da Pessoa com Deficiência). Disponível em: <http://www. planalto.gov.br/CCIVIL_03/Ato2015-2018/2015/Lei/L13146.htm>. Acesso em: 25 jun. 2020.

CARDOSO, V. D. et al. A contribuição da mídia na construção dos ídolos paralímpicos brasileiros. Cadernos de Educação, Tecnologia e Sociedade, v.11, n.1, p.78-86, 2018.

CASTRO, E. M.-de. et al. (2016). Fatores que afetam a carreira esportiva de alto rendimento do atleta com deficiência: uma análise crítica. Revista da Sobama, v.17, n.2, p.23-30, 2016.

CBE. OF/CBE/PRES/№2019.119. Decisão da IWAS - Cancelamento da Copa do Mundo e do Campeonato Regional das Américas de Esgrima em Cadeira de Rodas em razão da epidemia do coronavírus. 02 mar. 2020. Disponível em: <https://cbesgrima.org.br/wp-content/uploads/2020/03/of-2020-119-03-02-cancelacopa-regional-ecr.pdf>. Acesso em: 17 jun. 2020.

CPB. Esporte Paralímpico Em Tempos De Pandemia. [podcast] Papo Paralímpico. 18 mai. 2020. Disponível em: <https://podcasts.google.com/feed/aHR0cHM6Ly9h bmNob3luZm0vcy9mM2EyYWRjL3BvZGNhc3QvenNz/episode/NzA5ZDdmNDAtZjM5YS0 ONjNjLWI5NjItNWJkZGMzYzk4NzUzved=0CAkQzsICahcKEwjY68GNu5XqAhUAAAAAHQA AAAAQAQ>. Acesso em: 29 mai. 2020.

CPB Lança Programa de Acompanhamento aos atletas em quarentena. Site do CPB. 06 abr. 2020. Disponível em: <https://www.cpb.org.br/noticia/detalhe/2890/cpb-lancaprograma-de-acompanhamento-aos-atletas-em-quarentena >. Acesso em: 1 jun. 2020. 
CPB Protocola denúncia contra "humoristas"; Leia nota. Site do CPB. 13 abr. 2020. Disponível em: <https://www.cpb.org.br/noticia/detalhe/2895/cpb-protocola-denunciacontra-humoristas-leia-nota>. Acesso em: 2 jun. 2020.

DIAS, C. Trabalho, lazer e o novo coronavírus. História(s) do Sport. 11 mai. 2020. Disponível em: <https://historiadoesporte.wordpress.com/author/cleberdias/>. Acesso em: 15 jun. 2020.

FEDERAÇÃO Equestre Internacional destaca carreira do brasileiro Rodolpho Riskalla. Site do CPB. 13 mai. 2020. Disponível em: <https://www.cpb.org.br/noticia/ detalhe/ 2916/federacao-equestre-internacional-destaca-carreira-do-brasileiro-rodolphoriskalla>. Acesso em: 3 jun. 2020.

FLICK, U. Introdução à pesquisa qualitativa. Porto Alegre: Artmed, 2009.

HAIACHI, M. C. et al. Different views of (dis)ability: Sport and its impact on the lives of women athletes with disabilities. Journal of Physical Education and Sport, v.18, n.1, p.55-61, 2018.

HILLESHEIM, B.; CAPPELLARI, A. Os corpos da inclusão: mídia e relações com a diferença. Revista Educação Especial, v.32, p.1-17, 2019.

JODELET, D. As representações sociais. Rio de Janeiro: UERJ, 2001.

JOGOS Paralímpicos de Tóquio serão em agosto de 2021. Site do CPB. 30 mar. 2020. Disponível em: <https://www.cpb.org.br/noticia/detalhe/2887/jogos-paralimpicos-detoquio-serao-em-agosto-de-2021>. Acesso em: 1 jun. 2020.

LIVE Paralímpica: campeã paralímpica Evani sonha com mais oportunidade para mulheres na bocha. Site do CPB. 19 mai. 2020b. Disponível em: <https://www. cpb.org.br/noticia/detalhe/ 2920/live-paralimpica-campea-paralimpica-evani-sonhacom-mais-oportunidade-para-mulheres-na-bocha>. Acesso em: 3 jun. 2020.

LIVE Paralímpica: conheça Débora Menezes, primeira brasileira garantida em Tóquio no parataekwondo. Site do CPB. 07 mai. 2020a. Disponível em: < https://www.cpb. org.br/noticia/ detalhe/2912/live-paralimpica-conheca-debora-menezes-primeirabrasileira-garantida-em-toquio-no-parataekwondo>. Acesso em: 3 jun. 2020.

MENDONÇA, T. de A. et al. Consciência do direito: via de acesso à cidadania da pessoa com deficiência. Educação, v.45, p.1-25, 2020.

MENSAGEM do CPB sobre o adiamento dos Jogos de Tóquio. Site do CPB. 24 mar. 2020. Disponível em: <https://www.cpb.org.br/noticia/detalhe/2885/mensagem-docpb-sobre-o-adiamento-dos-jogos-de-toquio >. Acesso em: 1 jun. 2020.

NOTA de pesar - Falecimento da atleta Eliane Côrrea. Site do CPB. 22 mar. 2020. Disponível em: <https://www.cpb.org.br/noticia/detalhe/2886/nota-de-pesar--falecimento-da-atleta-eliane-correa >. Acesso em: 1 jun. 2020. 
ONU. Policy brief: a disability-inclusive. Response to COVID-19. mai. 2020.

Disponível em: <https://unsdg.un.org/sites/default/files/2020-05/Policy-Brief-ADisability-Inclusive-Response-to-COVID-19.pdf>. Acesso em: 20 jun. 2020.

SANCHOTENE, V. C. et al. Recordações de atletas do voleibol sentado acerca dos Jogos Paralímpicos (2012 E 2016). In: MISSIAS-MOREIRA, R.; COLLARES-DA-ROCHA, J. C. C.; SERVO, M. L. S. (Orgs.). Representações sociais na contemporaneidade. Curitiba: CRV, 2020. p.105-118. 